\title{
Prevalência do complexo teníase-cisticercose na zona rural do município de Viçosa, Minas Gerais
}

\author{
Prevalence of taeniasis-cysticercosis complex in the rural area of Viçosa-MG, Brazil
}

\author{
Adriana Felix Iasbik ${ }^{\mathrm{I}}$ Paulo Sérgio de Arruda Pinto ${ }^{\mathrm{II}}$ Paula Dias Bevilacqua ${ }^{\mathrm{II}}$ \\ Luis Augusto Nero ${ }^{\text {II }}$ Tatiane de Oliveira Santos" Adriano Groppo Felippe ${ }^{\text {II }}$
}

\begin{abstract}
A teníase é uma doença que se manifesta no ser RESUMO humano em decorrência da presença da forma adulta da Taenia sp., enquanto a cisticercose decorre da infecção pelo estágio larvar da Taenia sp. ou Taenia solium, no caso dos suínos e humanos. Foi realizado um estudo transversal visando a determinar a prevalência de cisticercose em suínos e de teníase em 176 propriedades localizadas na zona rural de Viçosa, Minas Gerais (MG). Foram coletadas amostras de sangue de 226 suínos e fezes de 266 humanos, além da realização de um inquérito epidemiológico. Não foi identificada teníase humana, e a prevalência da cisticercose suína foi de $0,4 \%$. As informações obtidas mostraram que a maioria das pessoas possuía o hábito de consumir carne suína não inspecionada; entretanto, todas as pessoas se alimentavam da carne bem aquecida. Em apenas 1,1\% das propriedades, o esgoto era depositado diretamente no solo e em 99,4\% destas a água era canalizada, enquanto $88,1 \%$ dos suínos eram criados presos. Concluiu-se que, na zona rural do município de Viçosa-MG, a prevalência do complexo teníase-cisticercose foi baixa, mostrando ainda um nível de contaminação inferior ao de outros municípios onde o complexo foi estudado.
\end{abstract}

Palavras-chave: saúde pública, prevalência, cisticercose suína, teníase humana.

\section{ABSTRACT}

Taeniasis occurs due to the presence of the adult form of Taenia sp. in human beings, and cysticercosis is caused by the presence of the larval stage of T. solium in pigs and humans. A transversal study was conducted aiming to determine the prevalence of porcine cysticercosis and taeniasis in 176 farms located in rural areas of Viçosa-MG. Blood samples of 226 pigs, and feces samples of 266 humans were collected. An epidemiological survey has also been done. We found a prevalence of $0.4 \%$ of porcine cysticercosis and taeniasis has not been found. The epidemiological data has shown that although most people consumed non-inspected pork, it used to be prepared well-done. Data showed that $88.1 \%$ of the pigs are reared in confinement in only $1.1 \%$ of the properties the sewer was disposed on the soil, and $99.4 \%$ used pipes for water distribution. It can be concluded that the prevalence of the taeniasis-cysticercosis complex in rural areas of Viçosa (State of Minas Gerais) is lower than in other similar regions.

Key words: public health, prevalence, porcine cysticercosis, human teniasis.

O complexo teníase-cisticercose constituise de duas doenças distintas, causadas pela mesma espécie de cestódeo, em fases diferentes do seu ciclo biológico, sendo a teníase caracterizada pela presença das formas adultas de Taenia solium ou Taenia saginata no intestino delgado do ser humano. A cisticercose é causada pela presença, nos tecidos do estágio larvar, de $\boldsymbol{T}$. saginata, em bovinos, ou $\boldsymbol{T}$. solium, em suínos e seres humanos, que ingeriram ovos das respectivas tênias (PAWLOWSKI et al., 2005).

O conhecimento da prevalência da doença tanto em humanos, como em animais é limitado. Nos animais, geralmente os dados são isolados, não

'Instituto Mineiro de Agropecuária, Secretaria de Estado da Agricultura de Minas Gerais, Belo Horizonte, MG, Brasil.

IIDepartamento de Veterinária, Universidade Federal de Viçosa (UFV), 36570-000, Viçosa, MG, Brasil. E-mail: pintopsa@ufv.br.

*Autor para correspondência. 
ordenados e não comparáveis, muitas vezes baseados em levantamentos feitos em matadouros fiscalizados pelos serviços de inspeção, principalmente federal.

Acompanhando a evolução tecnológica e sanitária da suinocultura, a prevalência da cisticercose suína tem mostrado sinais de queda nas últimas décadas. Relatos antigos apresentavam prevalências de cisticercose suína acima de 5\% no Estado de Minas Gerais (BRANT et al., 1969). Desde a década de 1980, o Estado de Santa Catarina, tradicional na produção de suínos com alta tecnologia, apresenta índices inferiores a $0,1 \%$ de prevalência para a cisticercose suína (RENÚNCIO, 1997), porém relatos oriundos de criações artesanais persistem apresentando prevalências bem superiores.

GOTTSCHALK et al. (2006) encontraram 20,5\% de soroprevalência de cisticercose suína pelo teste ELISA em criações de fundo de quintal localizadas na microrregião de Registro, São Paulo (SP). Em abatedouro de Barbalha, Ceará (CE), a prevalência da cisticercose em suínos provenientes de instalações rústicas foi de $4,7 \%$, enquanto que a teníase correspondeu a $1,1 \%$ das verminoses diagnosticadas pela Secretaria de Saúde desse município (SILVA et al., 2007).

Com os objetivos de determinar a prevalência de cisticercose suína e teníase humana e analisar dados sobre as condições sanitárias relacionadas ao padrão de alimentação e higiene pessoal e da criação de suínos, na zona rural do município de Viçosa-MG, foi realizado um estudo do tipo transversal, no período de março a agosto de 2007, envolvendo propriedades com criação artesanal de suínos. Para a seleção das propriedades, optou-se pela amostragem aleatória simples, considerando uma prevalência estimada de $1 \%$ de propriedades positivas para a cisticercose, uma precisão de $1 \%$ e um nível de significância de 5\%. O cálculo do tamanho da amostragem resultou em 176 propriedades, sendo utilizado o Programa EpiInfo (WHO, 2005). Das propriedades sorteadas, foram coletadas amostras de sangue de todos os 226 suínos criados e de fezes das 266 pessoas residentes nestas, sendo estas submetidas ao exame parasitológico pela pesquisa de ovos de enteroparasitas pelo método de Hoffman (SILVA, 2005).

A coleta de sangue de suínos foi realizada por punção do plexo orbitário, sendo as amostras dessoradas à temperatura ambiente e estocadas a $-20^{\circ} \mathrm{C}$, no mesmo dia. O diagnóstico sorológico da cisticercose suína foi realizado por triagem, pelo teste imunoensaio enzimático (ELISA) para pesquisa de anticorpos IgG anti-Cysticercus cellulosae, e os casos positivos foram submetidos ao Immunoblot para confirmação, conforme metodologias empregadas por PINTO et al. (2000) e PINTO et al. (2001), respectivamente. O antígeno utilizado foi o total de Taenia crassiceps, e os soros de suínos com e sem lesão de cisticercose ao abate foram empregados como controle positivo e controle negativo, respectivamente. Na determinação do ponto de corte no teste ELISA, utilizou-se a média das densidades ópticas dos soros-controle negativos, acrescida de três desvios-padrão.

No questionário epidemiológico, foram coletadas informações sobre as condições sanitárias das propriedades, relacionadas ao sistema de criação animal, à higiene pessoal e ao padrão da alimentação, da moradia e das instalações dos animais. O referido questionário foi testado previamente e aplicado em todas as propriedades por um mesmo entrevistador na forma aberta. As informações extraídas do questionário foram armazenados em bancos de dados do Programa EpiInfo, versão 3.3.2, e em seguida foram submetidos à análise estatística descritiva, utilizando o mesmo programa (WHO, 2005).

O teste ELISA revelou que, das 176 propriedades amostradas, 2,8\% apresentaram suínos soropositivos para a cisticercose, correspondendo a 2,2\% dos 226 suínos criados. Pelo teste Immunoblot, em $0,6 \%$ das 176 propriedades, foi confirmada a presença de suínos soropositivos. Considerando que apenas um animal confirmou resultado positivo, a prevalência da cisticercose suína na zona rural do município de Viçosa-MG, entre março de 2007 e agosto de 2007 , foi de $0,4 \%$. O suíno positivo para cisticercose foi encontrado na mesma comunidade rural onde PINTO et al. (2002) estimaram anteriormente uma soroprevalência de 1,8\% para cisticercose suína por meio do teste ELISA, configurando um resultado semelhante ao da presente pesquisa. O Immunoblot apresenta-se como uma alternativa mais específica de diagnóstico imunológico da cisticercose suína, entretanto o seu custo elevado tem levado à adoção do teste ELISA em estudos de prevalência (PINTO et al., 2001). Em relação ao resultado do exame coproparasitológico, todas as amostras foram negativas para a teníase.

Diferentemente de outras localidades onde foram encontradas altas prevalências da cisticercose em suínos criados artesanalmente (GOTTSCHALK et al., 2006; SILVA et al., 2007), ressalta-se que a prevalência foi baixa na zona rural do município de Viçosa-MG. Os resultados encontrados também acompanham a tendência de declínio da prevalência da cisticercose suína, observada nas últimas décadas pelos registros oficiais de inspeção (BRANT et al., 1969; PINTO et al., 2002). 
Na caracterização do perfil sanitário e sócioeconômico das propriedades e de seus moradores, verificou-se uma heterogeneidade nos indicadores pesquisados, que podem influenciar a ocorrência do complexo teníase-cisticercose.

Em relação ao sistema de criação dos suínos: em $88,1 \%$ das propriedades, os suínos ficavam sempre presos, em 6,8\% ficavam sempre soltos e em 5,1\% alternavam entre soltos e presos.

Em 72,7\% das propriedades, a forma de preparo da carne suína era frita; em $13,9 \%$, cozida ou frita; em $12,8 \%$, frita ou assada; e em $0,6 \%$, cozida, frita ou assada.

Em 99,4\% das propriedades, a água era canalizada; $100 \%$ das propriedades armazenavam a água em caixa própria. Em 98,3\% delas, as caixas eram tampadas; e em $79,5 \%$ das propriedades a caixa apresentava boas condições de higiene e conservação. As instalações do esgoto sanitário eram canalizadas em $98,9 \%$ das propriedades.

Observa-se então que, em Viçosa-MG, foram encontradas condições favoráveis ao controle do complexo teníase-cisticercose como: a criação dos suínos sempre presos em $88,1 \%$ das propriedades, a deposição de esgoto diretamente no solo em apenas 1,1\% e o hábito das pessoas de preparar a carne suína bem aquecida em $97,7 \%$ das propriedades. Todas essas medidas dificultam o acesso dos animais às fezes humanas ou a ingestão de carne suína contaminada com cisticercos viáveis (PAWLOWSKI et al., 2005; FLISSER et al., 2006).

$\mathrm{Na}$ propriedade de origem do suíno soropositivo, as condições gerais de saneamento eram adequadas, a renda familiar era de $R \$ 800,00$, e os suínos eram criados presos em instalação rústica; entretanto, os animais ingeriam água não tratada e sobras de alimentos caseiros. A família tinha o hábito de consumir carne suína não inspecionada, mostrando algumas falhas de ordem higiênica que poderiam explicar a presença do animal positivo (FLISSER et al., 2006).

A renda média dos proprietários rurais de Viçosa-MG e as condições de saneamento básico observadas quanto aos padrões de abastecimento de água e destinação do esgoto e do lixo são compatíveis com a baixa prevalência do complexo teníasecisticercose no município. Esse quadro contrasta com a realidade epidemiológica da área rural de outros municípios, que apresentaram piores condições de saneamento rural e criação de suínos, associadas à alta prevalência da cisticercose suína (SAKAI et al., 2001; PAWLOWSKI et al., 2005; GOTTSCHALK et al., 2006).
Concluiu-se que, na zona rural do município de Viçosa-MG, a prevalência do complexo teníasecisticercose foi baixa, mostrando uma taxa de $0,4 \%$ para a cisticercose suína, que é compatível com a ausência da teníase e as condições sanitárias relacionadas aos padrões de alimentação, higiene, criação de suínos e saneamento básico encontrados, que eram favoráveis ao controle do complexo teníase-cisticercose.

\section{AGRADECIMENTO}

Os autores agradecem à Fundação de Apoio à Pesquisa do Estado de Minas Gerais (FAPEMIG) e ao Conselho Nacional de Desenvolvimento Científico e Tecnológico (CNPq), pelo financiamento da respectiva pesquisa.

\section{COMITÊ DE ÉTICA E BIOSSEGURANÇA}

Esta pesquisa foi aprovada pela Comissão de Ética em Pesquisa com Animais (Processo 047-2007) e pelo Comitê de Ética em Pesquisa com Seres Humanos (Processo 075-2007), ambos vinculados à Universidade Federal de Viçosa.

\section{REFERÊNCIAS}

BRANT, P.C. et al. Ocorrência de cisticercose suína no decênio de 1959 a 1968. Arquivo da Escola de Veterinária, v.21, p.17-21, 1969.

FLISSER, A. et al. Control of the taeniosis/cysticercosis complex: future developments. Veterinary Parasitology, v.139, p.283-292, 2006. Disponível em: <http://dx.doi.org/ 10.1016/j.vetpar.2006.04.019>. Acesso em: 18 jun. 2010. doi:10.1016/j.vetpar.2006.04.019.

GOTTSCHALK, S. et al. Soroprevalência e aspectos epidemiológicos da cisticercose suína em criações de "fundo de quintal” na microrregião de Registro-SP. Veterinária e Zootecnia, v.3, n.2, p.192-200, 2006.

PAWLOWSKI, Z. et al. Control of Taenia solium taeniasis/ cysticercosis: from research towards implementation. International Journal for Parasitology, v.35, n.11-12, p.1221-1232, 2005. Disponível em: <http://dx.doi.org/ 10.1016/ j.ijpara.2005.07.015>. Acesso em: 18 jun. 2010. doi:10.1016/j.ijpara.2005.07.015.

PINTO, P.S.A. et al. Performance of the ELISA test for swine cysticercosis using antigens of Taenia solium and Taenia crassiceps cysticerci. Veterinary Parasitology, v.88, p.127130, 2000. Disponível em: <http://dx.doi.org/10.1016/S03044017(99)00201-0>. Acesso em: 18 jun. 2010. doi:10.1016/ S0304-4017(99)00201-0.

PINTO, P.S.A. et al. Immunoblot analisys using antigens from Taenia crassiceps cysticerci in the diagnosis of swine cysticercosis. Boletin Chileno de Parasitologia, v.56, n.12, p.36-42, 2001. Disponível em: <http://www.scielo.cl/ scielo.php? script = sci_art text\&pid=S0365$94022001000100010 \& \operatorname{lng}=$ es $\& n r m=i s o \& \operatorname{lng}=e n>$. Acesso em: 18 jun. 2010. doi: 10.4067/S0365-94022001000100010. 
PINTO, P.S.A. et al. Cysticercosis occurrence and sanitary risk in groups of inspected and non inspected swine in Brazil. Parasitologia Latinoamericana, v.57, n.3-4, p.129-133, 2002. Disponível em: $<$ http://www.scielo.cl/scielo.php?script=sci_arttext\&pid=S0717$77122002000300008 \& \operatorname{lng}=\mathrm{es} \& n \mathrm{~m}=\mathrm{iso} \& \ln \mathrm{ln}=\mathrm{en}>$. Acesso em: 18 jun. 2010. doi: 10.4067/S0717-77122002000300008.

RENÚNCIO A. Complexo teníase-cisticercose em Santa Catarina. In: SEMINÁRIO BRASILEIRO DE PARASITOLOGIA VETERINÁRIA, 10; SEMINÁRIO DE PARASITOLOGIA VETERINÁRIA DOS PAÍSES DO MERCOSUL, 1997, Itapema, SC. Anais... Itajaí, SC: Sociedade Brasileira de Parasitologia Veterinária, 1997. p.447-451.

SAKAI, H. et al. Seroprevalence of Taenia solium cysticercosis in pigs in Bahia State, Northeastern Brazil. American Journal of Tropical Medicine and Hygiene, v.64, n.5-6, p.268-269,
2001. Disponível em: <http://www.ajtmh.org/cgi/reprint/64/5/ 268>. Acesso em: 18 jun. 2010.

SILVA, A.V.M. Teníase e cisticercose. In: NEVES, D.P Parasitologia humana. 11.ed. São Paulo: Atheneu, 2005. Cap.25, p.227-237.

SILVA, M.C. et al. Cisticercose suína, teníase e neurocisticercose no município de Barbalha, Ceará. Arquivo Brasileiro de Medicina Veterinaria e Zootecnia, v.59, n.2, p.371-375, 2007. Disponível em: <http://www.scielo.br/pdf/abmvz/v59n2/ 16.pdf $>$. Acesso em: 18 jun. 2010.

WORLD HEALTH ORGANIZATION - WHO. EpiInfo. Database and statistics software for public health professionals. Centers for disease control and prevention (CDC). Versão 3.3.2. Atlanta,USA, 2005. Disponível em: <www.cdc.gov/epiinfo/downloads.htm>. Acesso em: 18 jun. 2010 . 